\title{
REFLEXÕES SOBRE CIDADANIA: DO CONTEXTO DE CRISE AS CONTRIBUIÇÕES DO MODELO RADICAL E PLURAL
}

\author{
Michel Belmiro Ilibio* \\ Reginaldo de Souza Viera**
}

\begin{abstract}
Resumo: O presente estudo tem por escopo investigar as relações entre cidadania e a teoria de democracia radical e plural. Inicialmente com uma breve digressão contextualizando a crise da cidadania na democracia representativa, procura-se pontuar algumas insuficiências desse modelo. As peculiaridades de uma democracia radical e plural, bem como a proposta de uma "nova" cidadania têm como marco teórico as propostas de Chantal Mouffe. O método de pesquisa utilizado foi o hipotético-dedutivo, com a análise qualitativa da bibliografia elegida. Adotou-se o método de procedimento o monográfico e empregou-se a técnica de pesquisa bibliográfica.
\end{abstract}

Palavras-chave: Cidadania; Crise de Representação; Democracia; Democracia Radical e Plural; Sociedade.

\section{REFLECTIONS ON CITIZENSHIP: FROM THE CONTEXT OF CRISIS THE CONTRIBUTIONS OF THE RADICAL AND PLURAL MODEL}

\begin{abstract}
The present study has as scope to investigate the relations between citizenship and the theory of radical and plural democracy. Initially with a brief digression contextualizing the crisis of citizenship in representative democracy, we try to punctuate some shortcomings of this model. The peculiarities of a radical and plural democracy, as well as the proposal of a "new" citizenship have Chantal Mouffe's proposals as a theoretical framework. The research method used was hypothetical-deductive, with the qualitative analysis of the chosen bibliography. The monographic method of procedure was adopted and the technique of bibliographic research was used.
\end{abstract}

\footnotetext{
* Mestrando em Direito pelo Programa de Pós-graduação em Direito - Mestrado, da Universidade do Extremo Sul Catarinense, com bolsa Prosuc/CAPES, na linha de pesquisa em Direito, Sociedade e Estado. Bacharel em Direito pela Universidade do Extremo Sul Catarinense (2016). Integrante do Núcleo de Estudos em Estado, Política e Direito (NUPED/UNESC) e do Laboratório de Direito Sanitário e Saúde Coletiva (LADSSC/UNESC).

** Doutor (2013) e Mestre (2002) em Direito pelo Programa de Pós-graduação em Direito - Mestrado e Doutorado, da Universidade Federal de Santa Catarina. Professor, pesquisador e Coordenador Adjunto do Programa de Pós-Graduação em Direito (PPGD/UNESC). Professor e pesquisador do Programa de Pós-Graduação em Desenvolvimento Socioeconômico (PPGDS/UNESC). Professor titular da Universidade do Extremo Sul Catarinense, atuando nos cursos de Direito e Odontologia. Coordenador do Núcleo de Estudos em Estado, Política e Direito (NUPED/UNESC) e do Laboratório de Direito Sanitário e Saúde Coletiva (LADSSC/UNESC). Membro titular da rede Ibero-americana de Direito Sanitário. Advogado.
} 
Keywords: Citizenship; Representation Crisis; Democracy Radical and Plural; Democracy; Society.

\section{1- INTRODUÇÃO}

O pensamento liberal inaugurou e constituiu a moderna concepção de democracia a partir de dois princípios fundamentais, a saber: a liberdade e a igualdade. Ambos os princípios, consolidados pelas revoluções burguesas dos séculos XVII e XVIII, possibilitaram romper com a ordem feudal existente, consolidando o capitalismo e usando o Estado para atender aos interesses próprios da nova classe em ascensão. Desse modo, a democracia liberal não surge apenas como a união de duas tradições distintas de pensamento, a saber: o liberalismo e a democracia, pelo contrário, a conjugação destas duas tradições de pensamento representou algo completamente novo dentro do pensamento político, que tem influenciado a teoria democrática até nossos dias atuais.

O modelo representativo de democracia foi a alternativa construída pelos teóricos liberais como vistas a consolidar o poder político da burguesia e evitar o exercício da democracia direta pela sociedade. Nesta nova configuração a sociedade (coletividade) não se reúne mais em volta de "assembleias" ou "praças" para fazer leis ou deliberar sobre as "coisas públicas", pois isso cabe a um corpo restrito de representantes eleitos por aqueles considerados cidadãos.

Ocorre que tal concepção tem contribuído para o processo de despolitização do cidadão na contemporaneidade, pois esse modelo não o possibilita atuar fora dos critérios formalmente estabelecidos.

Vieira (2013, p. 117) assinala que "esse processo retira da sociedade qualquer iniciativa no âmbito político e jurídico, e lhe deixa apenas um grande vazio, possibilitando-lhe apenas inserir-se nas relações privadas".

Entretanto, esse modelo encontra-se em crise. Uma crise do paradigma da representação do Estado moderno-liberal, que não mais consegue responder aos anseios de uma sociedade complexa. Portanto, estamos em um impasse, busca-se novos horizontes, a partir da teoria democrática, que possibilite repensar um novo modelo de cidadania que resgate o indivíduo dessa apatia política que vivenciamos. 
A discussão em torno da categoria cidadania é atual e urgente, além de ser um tema estratégico nos países de capitalismo periférico (o Brasil é exemplo) marcados por níveis elevados de desigualdades sociais e, por consequência, de grande exclusão social.

O objetivo central da pesquisa é investigar as relações entre cidadania e a teoria de democracia radical e plural proposta por Chantal Mouffe, de forma a contribuir com as reflexões que buscam alternativas para a crise de legitimidade do paradigma representativo de cidadania advindo da modernidade liberal.

O método utilizado no artigo foi o hipotético-dedutivo, pois partindo de um problema a investigação procura-se uma resposta por meio da análise qualitativa do referencial bibliográfico elegido para o estudo. O método de procedimento adotado foi o monográfico. Além disso, empregou-se a técnica de pesquisa bibliográfica.

Para fins de investigação do objetivo central da pesquisa, o estudo foi desenvolvido em três partes: na primeira, será feita a análise da crise da cidadania no contexto da democracia representativa; já na segunda parte, será desenvolvido alguns aspectos da democracia radical e plural teorizada por Chantal Mouffe; e, por último, na terceira parte do estudo, com vistas a responder a problemática desta pesquisa, será realizada uma reflexão da cidadania no âmbito da democracia radical e plural.

\section{2 - A CRISE DA CIDADANIA NA DEMOCRACIA REPRESENTATIVA}

Para compreendermos a atual crise da cidadania no contexto da democracia representativa é importante contextualizarmos algumas características desse modelo. Bobbio (1998) nos lembra de que a democracia representativa foi a saída dos liberais para evitar o exercício direto da democracia. Uma das consequências de tal realidade foi a redefinição da concepção de participação no poder político, ou seja, resumida ao direito de eleger representantes para o parlamento e de ser eleito.

Sob outra perspectiva, ao analisar a transferência do processo democrático público de tomada de decisões, que delineava a comunidade, para um centro de poder situado acima da sociedade, Rosenfield (2003) comenta que isso acarretou uma reorganização política das 
relações humanas, resultando numa transformação dos próprios conceitos de "espaço público" ou de "governo da maioria".

Diante dessa reorganização política, "as categorias da filosofia política clássica tornaram-se insuficientes para a análise de um fenômenos político que, tal como uma substância, aceita várias aparências sem contudo modificar a sua significação essencial" (ROSENFIELD, 2003, p.13). E nesse sentido, "a democracia pode inclusive vir a significar uma mera aparência de participação política, embora seu sentido originário seja precisamente o de uma efetiva participação dos indivíduos nos assuntos públicos”. (ROSENFIELD, 2003, p.13)

Chantal Mouffe (1996) acrescenta a este debate a importância do reconhecimento do político, pois acredita que o modelo de democracia liberal falha no campo da política ao negar o caráter inegável do antagonismo. Para a filósofa da Universidade de Westminster, ambas as abordagens: racionalistas ou individualistas do liberalismo impedem o reconhecimento das identidades coletivas e são incapazes de proporcionar a compreensão da natureza pluralista e conflitiva do mundo social.

Segundo Rosenfield (2003, p. 46), a Democracia ampara-se num imaginário formado na "possibilidade histórica de uma nova comunidade política, aberta a pluralidade dos discursos e ações políticas, fazendo com que cada indivíduo possa igualmente participar da condução dos negócios públicos".

Embora alguns teóricos da democracia defendam uma concepção passiva de cidadania, logo, da não participação política de todos, este regime político indica, ao contrário, uma maior participação e consciência dos assuntos públicos, pois, se o cidadão se vê reduzido a dizer sim ou não a algo que lhe é imposto como escolha, ele termina por perder o sentido da comunidade. (ROSENFIELD, 2003, p. 47)

Outro aspecto que contribui para o esgotamento desse modelo "democrático representativo" é apresentado por Trindade (2003, p. 61) ao mencionar que, "a crise da representação política torna-se mais dramática nas sociedades contemporâneas submetidas à representação permanente e fluída dos meios de comunicação de massa".

Portanto, para superar esse quadro, se faz necessário "[...] associar a prática da cidadania democrática a uma nova concepção de representação política para transformar o Estado privatizado pelo patrimonialismo. (TRINDADE, 2003, p.65)

Deve ser registrado, que nem o advento do Estado Social de Direito conseguiu romper com o paradigma moderno, fulcrado na representação e no monismo jurídico, pois apesar de 
mitigar as consequências no modelo econômico capitalista, continuou a deixar a sociedade sem voz e visibilidade jurídica e política (VIEIRA, 2013)

Para fundamentar sua tese Vieira (2013, p.153-154) elenca cinco questões chaves para compreendermos tais motivos. A primeira é que pelo intermédio de seu poder de polícia, o Estado "preocupa-se mais com a violação ocorrida do que com o patrimônio coletivo a ser protegido"; a segunda, é que o Estado não garante à Sociedade exercer um papel de protagonismo, mas apenas de mero coadjuvante, pois não lhe confere a titularidade para defender os bens coletivos e fundamentais; a terceira, diz respeito à apropriação dos bens público-coletivos por meio da iniciativa privada e de empresas públicas sem a efetiva intervenção da Sociedade nesses procedimentos; a quarta questão apresentada, é que o Estado não define e executa as suas ações mediante "políticas públicas coletivas da Sociedade, construídas por meio do procedimento participativo e com fulcro no pluralismo político e jurídico" e por fim, a quinta questão é que ao reproduzir nos espaços oficiais de participação popular as práticas do modelo representativo, o Estado descaracteriza tais instâncias coletivas, "tornando-as promessas não cumpridas".

Diante deste contexto de isolamento que o indivíduo vive, teria como tarefa o regime político democrático recolocar o indivíduo ao lugar "da comunidade, ao lugar da solidariedade, onde o que é político pode ser visto e vivido por todos”. (ROSENFIELD, 2003, p.47)

\footnotetext{
A especificidade da democracia moderna reside numa concepção determinada do homem enquanto animal político, isto é, enquanto capacidade de agir, de criar, de tomar a palavra e de discorrer sobre o interesse comum. Porém, nosso século fez também a experiência trágica de que o homem é um animal apolítico e antipolítico [...] (ROSENFIELD, 2003, p.47).
}

Ressalta Vieira (2013) que a modernidade vive uma crise do paradigma liberal, crise está de legitimidade jurídica e política, pois os mitos modernos não conseguem mais responder as necessidades da sociedade que a cada dia é mais complexa. "A cidadania representada que afastou a Sociedade de sua prerrogativa política é contestada. A Sociedade cria e "força" o Estado a reconhecer outros espaços participativos para além daqueles institucionalizados na democracia representativa". (VIEIRA, 2013, p. 155)

Para Rosenfield, a "apatia política e a inércia dos cidadãos diante dos assuntos políticos tornam-se um problema estrutural da democracia moderna", pois o modelo de Estado democrático representativo "põe em cena um grupo ativo, encarregado da representação, e um 
grupo que, se permanece atomizado e voltado para a satisfação dos interesses materiais, tende à passividade”. (ROSENFIELD, 2003, p.75)

Uma sociedade cujo "barulho" não é o de uma discussão ou de uma polêmica expressando a pluralidade do social torna-se vítima de uma uniformização política e de um mutismo social. Calar a sociedade civil significa des-articular a pluralidade dos discursos políticos e não enunciar o que, de direito, corresponde à vida pública da sociedade. O discurso político que é um discurso de "opinião", ou melhor, de "opiniões", exprimindo a mutabilidade e a imprevisibilidade da práxis humana, pode então, sob determinadas condições históricas, tornar-se propriedade de um grupo político que pretende veicular a "verdade" das relações sociais e políticas. (ROSENFIELD, 2003, p.78)

Considerando as atuais problemáticas e insuficiências elencadas neste tópico concernentes a crise da cidadania na democracia representativa, necessário se faz estudar um novo marco teórico que ofereça uma alternativa e possibilite repensar o modelo de cidadania representativa. Para tanto, optou-se pela teoria de Chantal Mouffe, que propõe um modelo de Democracia Radical e Plural.

\section{3- A TEORIA DEMOCRÁTICA DE CHANTAL MOUFFE}

As bases teóricas sobre a Democracia Radical e Plural foram lançadas com a publicação de Hegemony and Socialist Strategy, em 1985, por Chantal Mouffe e Ernesto Laclau. A tese central do livro "é a de que a objetividade social é constituída por meio de atos de poder”. Segundo Mouffe, “isso implica que qualquer objetividade social é em última instância política e que ela tem de mostrar os traços de exclusão que governam a sua constituição". Essa linha entre a objetividade e o poder (a qual Mouffe denomina de ponto de convergência ou de arruinamento mútuo) é o que ela chama de "hegemonia". (2005, p.19)

\footnotetext{
Considerando-se que qualquer ordem política é a expressão de uma hegemonia, de um padrão específico de relações de poder, a prática política não pode ser entendida como simplesmente representando os interesses de identidades pré-constituídas, mas como constituindo essas próprias identidades em um terreno precário e sempre vulnerável. (MOUFFE, 2005, p.19)
}

Segundo Mouffe, ao aceitarmos que as relações de poder são constitutivas do social, a questão principal para a política democrática será de como constituir formas de poder mais compatíveis com valores democráticos. A autora menciona que "compreender a natureza constitutiva do poder implica abandonar o ideal de uma sociedade democrática como a realização de perfeita harmonia ou transparência”. (MOUFFE, 2005, p.19) 
A democracia requer, portanto, que a natureza puramente construída das relações sociais encontre seu complemento nos fundamentos puramente pragmáticos das pretensões de legitimidade do poder. Isso implica que não haja nenhuma lacuna insuperável entre poder e legitimidade [...] no sentido de que a) se qualquer poder é capaz de se impor, é porque foi reconhecido como legítimo em algumas partes e b) se a legitimidade não se baseia em um fundamento apriorístico, é porque se baseia em alguma forma de poder bem-sucedido. (MOUFFE, 2005, p.19)

Mouffe crítica à teoria deliberativa nesse ponto, pois a conexão entre poder e legitimidade e a ordem hegemônica que ela acarreta é renegada pelos deliberativistas ao estabelecerem "a possibilidade de um tipo racional de argumentação em que o poder foi eliminado e em que a legitimidade é fundada na racionalidade pura.” (2005, p.19-20)

Ao delimitar o terreno teórico, Mouffe (2005) prossegue com a formulação de uma alternativa (ao modelo agregativo e ao modelo deliberativo) que ela denomina de "pluralismo agonístico". Kozicki (2000, p. 138) ressalta que ao "aceitar a idéia de uma sociedade plural, é necessário excluir a possibilidade de uma sociedade que vive em harmonia, onde o conflito e o dissenso não existam.”

Para compreender o modelo de democracia agonística e plural, Mouffe (2005, p. 20) esclarece que uma primeira distinção é necessária nessa nova perspectiva: a distinção entre "política" e "o político".

Por "político" refirome à dimensão do antagonismo que é inerente a todas as sociedades humanas, antagonismo que pode assumir formas muito diferentes e emergir em relações sociais diversas. "Política", por outro lado, refere-se ao conjunto de práticas, discursos e instituições que procuram estabelecer uma certa ordem e organizar a coexistência humana em condições que são sempre potencialmente conflituosas, porque afetadas pela dimensão do "político". (MOUFFE, 2003, p.15)

Chantal Mouffe considera como questão chave para a política democrática, a necessidade de que reconheçamos "a dimensão do "político" e ao mesmo tempo entender que a "política" "consiste em domesticar a hostilidade e em tentar conter o potencial antagonismo que existe nas relações humanas." (2005, p. 20)

Segundo Kozicki (2000) é neste ponto, "do conflito e do antagonismo”, que a noção de democracia deliberativa (delineadas por Rawls e Habermas) não consegue captar.

Nestes autores, o pluralismo é sempre reconhecido, mas colocado na esfera privada, longe da esfera pública. As paixões, o conflito, os antagonismos, todos são inevitáveis. Mas a sua ocorrência se dá no âmbito da esfera privada, terreno regulado pelo princípio da liberdade. Na esfera pública os indivíduos seriam livres e iguais, agindo sempre de acordo com princípios racionais, os quais possibilitariam a obtenção de um consenso quanto aos diferentes tópicos da agenda política. O político, nesta ótica, ficaria isento do conflito. (KOZICKI, 2000, p. 138-139) 
Chamando a atenção para o papel central entre a relação de amigo/inimigo em política, Mouffe diz que "Schmitt leva-nos a tomar consciência da dimensão do político que está ligada a existência de um elemento de hostilidade entre os seres humanos”. (1996, p.13)

Conforme Ames (2012, p. 223) “a percepção da dimensão de "o político" leva a admitir que as questões políticas sempre implicam em decisões que requerem uma opção entre alternativas antagônicas".

Uma das idéias centrais de Schmitt é sua tese segundo a qual as identidades políticas
consistem num certo tipo de relação nós/eles, a relação amigo/inimigo. No campo das
identidades coletivas, trata-se sempre da criação de um "nós" que somente existe em
oposição a um "eles". Ainda que nem toda relação nós/eles se converta numa relação
amigo/inimigo (ou seja, numa relação "política"), se torna tal quando o "eles" é
percebido como negando a identidade do "nós". (AMES, 2012, p.223-224)

Desta forma, o político não pode estar limitado a um determinado tipo de instituição ou como "constituindo uma esfera ou nível especifico de sociedade", contrariamente, ele "tem de ser concebido como uma dimensão inerente a todas as sociedades humanas e que determina a nossa própria condição ontológica”. (MOUFFE, 1996. p.13)

Mouffe (1996, p. 15) salienta que ao "aceitarmos a necessidade do político e a impossibilidade de um mundo sem antagonismos", será necessário estabelecer uma forma de criar ou manter uma ordem democrática pluralista.

Segundo a filósofa a questão crucial para a política democrática é, como estabelecer uma distinção nós/eles, de uma forma que seja compatível com o reconhecimento do pluralismo, pois o conflito nas sociedades democráticas não pode ser erradicado, uma vez que a especificidade da democracia moderna reside precisamente, no reconhecimento e na legitimação do conflito (MOUFFE, 2006, p.21)

Chantal Mouffe afirma que o objetivo da política democrática consiste em transformar o antagonismo em agonismo, ou seja, o que importa é que o conflito não se torne um enfrentamento entre inimigos (antagonismo), mas tome a forma de um enfrentamento entre adversários (agonismo). (MOUFFE, 2006, p.21)

No modelo agonístico, a primeira tarefa da política democrática "não é eliminar as paixões ou relegá-las à esfera privada para estabelecer um consenso racional na esfera pública”, pelo contrário, "é "domesticar" essas paixões mobilizando-as para propósitos democráticos , mediante a criação de formas coletivas de identificação em torno de objetivos democráticos". (MOUFFE, 2006, p.22) 
Entende Kozicki (2000, p. 138) que "as paixões constituem uma mola extremamente importante na análise dos motivos que levam os indivíduos a atuar”. Para ela, estas paixões, são inerradicáveis, "tanto no processo de construção da identidade de cada um dos atores sociais", bem como "da convivência em sociedade", o que ira implicar "sempre na ocorrência de conflitos, antagonismos".

Adiante, Mouffe (2006, p.22) sustenta que a categoria central da política democrática é a categoria do adversário, esse com quem devemos "partilhar de uma lealdade comum aos princípios democráticos da liberdade e igualdade”.

Outro aspecto importante que deve ser observado na categoria de "adversário" é que no discurso liberal, adversário é simplesmente o competidor. Eles entendem que o campo da política é um terreno neutro, onde diferentes grupos competem para ocupar as posições de poder, objetivando apenas tomar o lugar do outro. Na concepção liberal, não se coloca em questão a hegemonia dominante ou têm-se preocupação em transformar as relações de poder, pois o que ocorre é uma competição de elites. (MOUFFE, 2006, p.22)

Na teoria radical e plural, a dimensão antagônica estará sempre presente, pois o que estará em jogo é a luta entre projetos hegemônicos opostos que nunca se reconciliarão racionalmente, pois trata-se de uma confrontação real, um confronto que se desenvolve sob condições reguladas por um conjunto de procedimentos democráticos aceito pelos adversários. (MOUFFE, 2006, p.22)

Alerta Mouffe (2006, p.22) que para funcionar adequadamente, a democracia requer o confronto entre posições políticas democráticas, pois caso não exista, haverá um perigo para que esse confronto seja substituído entre valores morais não negociáveis ou formas de identificação essencialistas, por isso acredita que devemos suspeitar da celebração em torno da diluição das fronteiras da esquerda e direita.

"Uma democraica que funcione adequadamente exige o confronto vital entre as posições políticas democráticas. Os antagonismos podem assumir muitas formas, e é ilusória a crença de que poderiam ser erradicados”. (MOUFFE, 2006, p.22)

Para transformar os antagonismos em relações agonísticas será necessário proporcionar uma saída política para a expressão do conflito no âmbito de um sistema democrático pluralista que ofereca possibilidades de identificação em torno de alternativas políticas democráticas. (MOUFFE, 2006, p.22) 
Ela esclarece que enquanto houver obstáculos para essa identificação política, haverá terreno para emergir variadas formas de políticas articuladas em torno de identidades essencialistas do tipo nacionalista, religiosas e étnicas, além da multiplicação de confrontos em torno de valores morais inegociáveis. (MOUFFE, 2006, p.22)

\begin{abstract}
Muita ênfase no consenso e a recusa de confrontação levam à apatia e ao desapreço pela participação política. Ainda pior, o resultado pode ser a cristalização de paixões coletivas em torno de questões que não podem ser manejadas [...] pelo processo democrático e uma explosão de antagonismo que pode desfiar os próprios fundamentos da civilidade. (MOUFFE, 2005, p.21)
\end{abstract}

Quando faltam as lutas políticas democráticas com as quais se identificar, o resultado é que "o opositor não pode ser concebido como um adversário com o qual se pode lutar, mas apenas como um inimigo que é necessário destruir". (MOUFFE, 1996, p.17)

O ideal de uma democracia pluralista não pode ser alcançar um consenso racional na esfera pública. "Devemos aceitar que cada consenso existe como resultado temporário de uma hegemonia provisória, como estabilização do poder e que ele sempre acarreta alguma forma de exclusão”. (MOUFFE, 2005, p.21)

Ao invés de disfarçar essas exclusões, ao adotar-se a perspectiva agonística busca-se "abrir caminho para o dissenso", e segundo Mouffe (2005, p.22) "promover as instituições em que este possa ser manifestado".

Portanto, longe de ser o resultado necessário de uma evolução moral da humanidade, a democracia é algo de incerto e improvável e nunca deve ser tida como garantida. É sempre uma conquista frágil, que precisa de ser defendida e aprofundada. (MOUFFE, 1996, p.17)

Ao adotarmos a perspectiva de democracia plural e radical, precisa-se conceber que tal democracia será sempre uma democracia futura, uma vez que conflito e antagonismo são condições de possibilidade e impossibilidade (respectivamente) da sua total realização. (MOUFFE, 1996, p.18)

Para Mouffe (1996 p. 18), "hoje em dia a questão crucial é a de como estabelecer uma nova fronteira política, capaz de dar um verdadeiro impulso à democracia”. A filósofa crê que isto exigirá uma "redefinição da esquerda como um horizonte em que as muitas lutas diferentes contra a sujeição possam encontrar um espaço de filiação”. (MOUFFE, 1996, p. 18)

Adotar uma noção de cidadania democrática radical revela-se fundamental para Chantal Mouffe, "porque é susceptível de facultar uma forma de identificação que permita o 
estabelecimento de uma identidade política comum entre várias lutas democráticas". (MOUFFE, 1996, p.18)

Considerando o contexto de crise da cidadania no modelo de democracia representativa no tópico anterior deste estudo, e sabendo da importância vital da cidadania para fortalecimento da política democrática, o próximo item irá debruçar-se em torno do tema, a partir da teorização de Chantal Mouffe.

\title{
4 - A CIDADANIA NO MODELO DE DEMOCRACIA RADICAL E PLURAL
}

Como compreender a cidadania dentro de uma perspectiva da teoria de democracia radical e plural de Chantal Mouffe?

Mouffe (1997a) considera que hoje, "temas da 'cidadania' e da 'comunidade' vêm sendo discutidos em muitas áreas da esquerda". Para ela, isso é decorrente "da crise da classe política e indica a consciência crescente da necessidade de uma nova forma de identificação, em torno da qual se organizam as forças em luta por uma radicalização da democracia”. (MOUFFE, 1997a, p.59)

Ela concorda que a questão da identidade política é importante, e considera fundamental que a política democrática tome por tarefa a tentativa de construir "identidades cidadãs". Conforme a autora, a forma como definimos a cidadania "está intimamente ligada ao tipo de sociedade e de comunidade política que desejamos”. (MOUFFE, 1997a, p.59)

\begin{abstract}
A concepção de cidadania que pretendo apresentar como a requerida por um projecto de democracia plural e radical é a de uma forma de identidade política que consiste numa identificação com os princípios políticos da democracia pluralista moderna, isto é, a afirmação da liberdade e da igualdade para todos. Seria a identidade política comum de pessoas que podem estar empenhadas em muitos empreendimentos diferentes e ter concepções divergentes de bem, mas que estão ligadas pela sua identificação comum com uma dada interpretação de um conjunto de valores éticopolíticos. (MOUFFE, 1996, p.113-114)
\end{abstract}

A construção do conceito de cidadania radical parte das reflexões de Chantal Mouffe ao envolver-se nos debates entre liberais e republicanos. A autora reconhece que embora existam problemas na concepção liberal de cidadania, também é consciente dos defeitos da solução do republicanismo cívico, portanto, a tarefa não é substituir uma tradição pela outra, mas sim "retirar elementos de ambas, conjugando-as numa nova concepção de cidadania, adequada a um projeto de democracia radical e plural." (MOUFFE, 1996, p.83-86) 
A nossa escolha não é apenas entre um agregado de indivíduos sem um interesse público comum e uma comunidade pré-moderna organizada em torno de uma única ideia substantiva de bem comum. O desafio fundamental é imaginar a comunidade política democrática moderna fora dessa dicotomia. (MOUFFE, 1996, p.90)

De forma sucinta, Kozicki (2000, p.121) elenca os elementos de contribuição do pensamento liberal, para a proposição de uma cidadania radical, tais como a idéia de "separação dos poderes, a separação entre a Igreja e o Estado e a aceitação do valor pluralismo [...]”.

Mouffe alerta que, ao mesmo tempo em que o liberalismo contribuiu para a formulação de uma "cidadania universal baseada na afirmação de que todos os indivíduos nascem livres e iguais", também reduziu a cidadania "a um mero estatuto legal, estabelecendo os direitos de que o indivíduo é titular em face ao Estado". Lembrando ainda que, para a maioria dos pensadores liberais, ideias de "empenhamento público, actividade cívica e participação política numa comunidade de iguais", foram estranhas a estes. (MOUFFE, 1996, p.86)

Já o contributo do republicanismo cívico, parte da necessidade de "reter a importância das noções de participação cívica, desenvolvimento comum de normas e valores" (KOZICKI, 2000, p. 121), além da noção de que a identidade do indivíduo constitui-se a partir da inserção deste em uma determinada comunidade. "Mas o problema surge com a exigência de conceber a comunidade política de uma maneira que seja compatível com a democracia moderna e o pluralismo liberal”. (MOUFFE, 1997a, p.60)

Chantal Mouffe (1996, p.85-86) concorda com a tese de que o conceito de cidadania, proposto pelo republicanismo cívico, pode levar-nos a um "risco real de regressarmos a uma concepção pré-moderna da política", isso por que, diferentemente "do que propõem alguns comunitaristas, uma comunidade política democrática moderna não pode ser organizada em torno de uma única ideia substantiva de bem comum".

Os liberais sustentam que as ideias sobre o "bem comum" só podem ter implicações totalitárias, e por isso são incompatíveis com as instituições democráticas. "A participação política ativa, dizem, é incompatível com a ideia moderna de liberdade. A liberdade individual somente pode ser compreendida de uma maneira negativa, como ausência de coerção". (MOUFFE, 1997a, p.60-61)

Para rebater as críticas dos liberalistas, Mouffe apresenta as contribuições de Quentin Skinner, que pontua que não há qualquer incompatibilidade entre a concepção republicana clássica de cidadania e a democracia moderna. 
Ele encontra em algumas formas de pensamento republicano, particularmente em Maquiavel, uma maneira de conceber a liberdade que, embora negativa - e portanto moderna -, inclui a participação política e a virtude cívica. É negativa porque a liberdade é concebida como a ausência de impedimentos à realização de nossas opções. Mas esta também assevera que é apenas como cidadãos de um "estado livre", de uma comunidade cujos membros participam ativamente no governo, que tal liberdade individual pode ser garantida. Para assegurar nossa própria liberdade e evitar a servidão, que tornaria seu exercício impossível, devemos cultivar virtudes cívicas e nos devotar ao bem comum. A idéia de um bem comum acima de nossos interesses privados é uma condição necessária para desfrutar da liberdade individual. (MOUFFE, 1997a, p.61)

Mouffe (1997a, p. 61)) considera o argumento de Skinner crucial para um projeto democrático radical, mas a filósofa elenca uma questão a ser respondida: qual seria o "tipo de comunidade política adequada a uma tal articulação entre os direitos dos indivíduos e a participação política do cidadão ?’.

O significado de cidadania que ela propõe, "implica encarar a cidadania, não como um estatuto legal, mas como uma forma de identificação, um tipo de identidade política: algo que deverá ser construído, e não empiricamente determinado.” (MOUFFE, 1996, p.90)

A autora procura uma forma de associação política que acomode "as distinções entre público e o privado, a moralidade e política" (estas, contribuições do liberalismo à democracia moderna) "sem renunciar a natureza ética da associação política". (MOUFFE, 1996, p.91)

Mouffe faz uso da distinção de Michael Oakeshott, entre societas e universitas (no livro On Human Conduct) para compreendermos dentro de qual contexto uma cidadania democrática radical poderia ser pensada.

Para a filósofa, a ideia de associação civil (ou societas) é mais adequada numa ótica da Democracia Radical, pois o que une os indivíduos é a "preocupação pública” ou "prática de civilidade" (ou respublica, conforme o autor). (MOUFFE, 1996, p.92).

Nos seu entendimento, "é uma forma de associação que pode ser constituída entre indivíduos relativamente estranhos, pertencentes a várias associações com objetivos específicos e cuja fidelidade a comunidades específicas não é considerada conflitante com a sua qualidade de membros da associação civil”. (MOUFFE, 1996, p. 92)

Conforme Mouffe (1996) são aspectos valiosos nesse tipo de associação o reconhecimento do pluralismo e da liberdade individual, não relegando à esfera privada da moralidade os aspectos normativos. Porém, para utilizarmos a noção de societas proposta por Oakeshott, precisa-se reconhecer a divisão e o antagonismo. 
Nesse sentido, reconhece Kozicki (2000, p. 124) que a cidadania não "pode ser entendida fora da perspectiva de que as relações existentes dentro do espaço público, constituídas a partir de ações políticas, exercitam-se sempre dentro de uma dimensão de conflito e antagonismo". Portanto, Chantal Mouffe (1997a, p. 65) reconhece que para "introduzir o conflito e o antagonismo no modelo de Oakeshott, é necessário reconhecer que a respublica é o produto de uma dada hegemonia, a expressão de relações de poder, e que pode ser desafiada".

Neste sentido, a concepção de cidadania proposta pode contribuir para resolver uma das principais dificuldades enfrentadas nas democracias pluralistas, qual seja: o estabelecimento de uma forma de consenso que não elimine o dissenso. (MOUFFE, 1997a, p.49)

"Tal conceito permite o desenvolvimento de uma figura chave em uma democracia pluralista: o adversário", dessa forma o oponente não é visto como um inimigo para destruir, mas como um adversário. "Lutamos contra as suas ideias, mas reconhecemos o direito de afirmá-las e defende-las.” (MOUFFE, 1997a, p.50)

Para Mouffe, se entendermos a cidadania como uma identidade política, criada através da identificação com a respublica, torna-se possível uma nova concepção de cidadão:

\begin{abstract}
Primeiro, estamos agora lidando com um tipo de identidade política, uma forma de identificação, não mais simplesmente com um status legal. O cidadão não é, como no liberalismo, alguém que é o recipiente passivo de direitos específicos e que goza da proteção da lei. Não é que aqueles elementos tornem-se irrelevantes, mas a definição de cidadão muda, porque a ênfase é colocada na identificação com respublica. É uma identidade política comum de pessoas que poderiam estar engajadas em muitos e diferentes empreendimentos de fins e com diversas concepções do bem, mas que aceitam se submeter ás regras prescritas pela respublica, na busca de suas satisfações e no desempenho de suas ações. (1997b, p.95)
\end{abstract}

Sob a perspectiva de Chantal Mouffe (1997b, p.96), a cidadania passa a ser vista como "um princípio articulador, que afecta as diferentes posições de sujeito do agente social [...], ao mesmo tempo que permite uma pluralidade de compromissos e o respeito pela liberdade individual".

Porém, Kozicki (2000, p.124-125) salienta que ao reconhecer a política como espaço de conflito e antagonismo, isso irá significar que os princípios políticos constitutivos da sociedade - no caso, liberdade e igualdade - recebam diferentes interpretações.

Estas diferentes interpretações vão gerar acordos quanto à maneira da condução da coisa pública, acordos que serão sempre parciais e provisórios, dada a impossibilidade de uma solução final e definitiva quanto ao significado destes princípios. A cidadania, na perspectiva da democracia radical, implica a identificação dos sujeitos com os princípios que são constitutivos desta matriz. Indo além da aceitação dos princípios 
da liberdade e igualdade, é necessário que o cidadão reconheça o valor e que haja uma identificação coletiva com diversos movimentos sociais, os quais pretendem aprofundar a realização daqueles princípios. (KOZICKI, 2000, p.125)

Assim, ao adotarmos uma interpretação democrática radical, pressupõe-se que os princípios da liberdade e igualdade "sejam entendidos de maneira que leve em consideração as diferentes relações sociais e posições de sujeito nas quais elas são relevantes: gênero, classe, raça, etnicidade, orientação sexual, etc". (MOUFFE, 1997a, p.66)

Em última análise, ela rejeita à idéia de que o exercício da cidadania consiste na adoção de um ponto de vista universal, "tornado equivalente à "razão" e reservado aos homens". A filósofa reconhece que haverá tantas formas de cidadania quantas forem as interpretações dos princípios de liberdade e igualdade. (MOUFFE, 1996, p.98).

Sob a ótica da democracia radical, a distinção entre o público e o privado não é abandonada, mas reformulada, e novamente, buscando contribuições de Oakeshott, Mouffe apresenta alternativa às limitações do liberalismo.

Segundo ele, a societas é uma condição civil em que todos os empreendimentos são privados, embora nunca isentos das condições públicas especificadas na respublica. Numa societas, todas as situações são um encontro entre o "privado" e o "público", entre uma acção ou um discurso, para obter uma satisfação substantiva imaginada ou desejada e as condições de civilidade a subscrever na sua execução e nenhuma situação implica a exclusão de qualquer outra. (1997b, p. 98)

Deste modo, os desejos, as escolhas e as decisões seriam privados, porque é de responsabilidade de cada indivíduo, mas os desempenhos são públicos porque exige-se que se submetam às condições especificadas na respublica. Como não existem regras na respublica que impõem, proíbem, ou garantem ações ou discursos substantivos, não dizendo aos agentes o que devem fazer, ela tornará viável como modo de associação que respeita a liberdade individual. (MOUFFE, 1996, p.98)

A pertença do indivíduo à comunidade política e a sua identificação com os respectivos princípios ético-políticos manifestam-se pela sua aceitação do interesse comum expresso na respublica. Fornece a gramática da conduta do cidadão. No caso de um cidadão democrata radical, uma tal abordagem permite-nos visualizar a forma como uma preocupação de igualdade e liberdade deve informar as suas acções em todas as áreas da vida social (MOUFFE, 1996, p.98-99)

Mantém-se a distinção "privado" (liberdade individual) e o público (respublica), tal como a distinção indivíduo/cidadão. Não se diz mais "aqui terminam os meus deveres como cidadão e começa a minha liberdade como indivíduo". Estas duas identidades convivem numa tensão permanente, caracterizando a democracia moderna, e a tentativa de impor uma perfeita 
harmonia, para alcançar uma "verdadeira" democracia, pode apenas conduzir à sua destruição (MOUFFE, 1996, p. 99).

Por essa razão, o projeto de uma democracia plural e radical reconhece a impossibilidade de uma realização completa da democracia e da realização final da comunidade política. (MOUFFE, 1996, p. 99)

Apropriando-se novamente das palavras de Mouffe (1996, p. 99) pode-se afirmar que seu objetivo é usar os recursos simbólicos da tradição democrática liberal para a luta e para aprofundamento da revolução democrática, sabendo ser este um processo sem fim. Por fim, ao conjugar o ideal dos direitos e do pluralismo com ideias de diligência pública e de preocupação ético-política, essa nova concepção de cidadania proposta irá contribuir significativamente para a extensão dos princípios da liberdade e da igualdade além de restituir dignidade à política.

\section{5- CONSIDERAÇÕES FINAIS}

Se na pré-modernidade os cidadãos participavam diretamente na gerência da "coisa pública", possibilitando uma participação ativa sobre os assuntos da política, com o surgimento do Estado Moderno Liberal se abstrai essa prerrogativa dos cidadãos (sociedade/coletividade), relegando a estes o mero formalismo político (direito ao voto).

Neste modelo, a sociedade (como elemento essencial da cidadania) torna-se estranha ao sujeito individual, pois este se enxerga apenas como cidadão eleitor. Isso tem implicações diretas no ambiente público de participação, que passa a ser controlado nos moldes do Estado Liberal.

Outro aspecto apontado por Chantal Mouffe é que a partir do colapso do comunismo real, com a desintegração da União Soviética, vivemos um suposto desaparecimento da oposição entre esquerda/direita, o que para a maioria dos teóricos liberais, significa que os antagonismos foram superados. Isso é um equívoco. Os antagonismos continuam existindo, só estão sendo escondidos ou mascarados.

Diferente dos teóricos liberais, Mouffe apresenta como elementos centrais a legitimação do conflito e a valorização do dissenso, pois para ela este consenso representa apenas uma hegemonia provisória. Neste sentido a autora formula um modelo radical e plural de democracia que, não só reconhece o conflito como também o considera essencial para a própria democracia.

Revista de Teoria e Filosofia do Estado | e-ISSN: 2525-9652 | Maranhão | v. 3 | n. 2 | p. 58 - 75 | Jul/Dez. 2017. 
A partir da valorização da esfera política, propõe-se um conceito de cidadania radical. Chantal Mouffe não pretende substituir uma tradição pela outra, pelo contrário, ela busca elementos que podem ser aproveitados tanto da noção liberal, quanto do republicanismo cívico de cidadão. Ou seja, procura estabelecer uma cidadania que conjugue pluralismo (proteção dos direitos individuais) e participação política.

Afirmando ser a cidadania vital para a política democrática, necessariamente a teoria democrática moderna tem de criar espaços para concepções divergentes, enquanto cidadãos constituídos por identidades específicas. A cidadania radical será aquela exercida em uma esfera pública marcada pelo conflito e pelo antagonismo, visualizando o outro como “adversário" e não um "inimigo" a quem deve-se destruir.

Neste sentido, a categoria cidadania não pode ser analisada no contexto de uma paisagem simplista, tendo em vista ser complexa e contraditória, como o é a própria sociedade.

Portanto, depreende-se deste estudo a preocupação de Mouffe de conceber um cidadão comprometido com o aprofundamento radical da democracia, não abandonando as conquistas liberais, mas procurando retirá-lo da apatia política, inserindo-o e também a sociedade a arena política, a ágora da democracia em sua concepção plena de participação.

\section{REFERENCIAS}

AMES, José Luiz. Republicanismo conflictual y agonismo democrático pluralista: un diálogo entre maquiavelo y chantal mouffe. Príncipios Rev. de Filosofia. Natal (RN), v. 19, n. 31 Janeiro/Junho de 2012, p. 209-234. Disponível em: < http://www.principios.cchla.ufrn.br /arquivos/31P-209-234.pdf > Acesso em: 03 abr.2017.

BOBBIO, Norberto. Verbete: democracia. In: BOBBIO, Norberto; MATTEUCCI, Nicola; PASQUINO, Gianfranco (Orgs.). Dicionário de política. 2 volumes. Tradução de Carmen C. Varriale, Gaetano lo Mônaco, João Ferreira, Luís Guerreiro Pinto Cacais e Renzo Dini. Rev. geral de João Ferreira e Luís Guerreiro Pinto Cacais. 11ª . ed. Brasília: Editora Universidade de Brasília, 1998. p. 323-324.

KOZICKI, K. Conflito e estabilização: comprometendo radicalmente a aplicação do direito com a democracia nas sociedades contemporâneas. 2000. 266p. Tese (Doutorado em Direito). Curso de Pós-Graduação em Direito, Universidade Federal de Santa Catarina. Florianópolis, 2000 . 
MOUFFE, Chantal. Democracia, cidadania e a questão do pluralismo. In: Política \& Sociedade, Florianópolis, v.2, n.3, 2003, p.11-26.

MOUFFE, Chantal. Por um modelo agonístico de democracia. Rev. Sociol. Polít., Curitiba, n. 25, p. 11-23, nov. 2005.

MOUFFE, Chantal.O Regresso do Político. Trad. Ana Cecília Simões. Lisboa: Gradiva, 1996.

MOUFFE, Chantal. Por um modelo agonístico de democracia. Rev. Sociologia Política. Curitiba, n. 25, p. 165-175, 2006. Disponível em: <ojs.c3sl.ufpr.br/ojs/index.php/rsp/article/viewFile/7071/ 5043 > Acesso em: 27 mai. 2017.

MOUFFE, Chantal. A cidadania democrática e a comunidade política. Estudos de Sociologia, São Paulo. v.2, n.2, p.59-68. 1997a. Disponível em:< http://seer.fclar.unesp.br/estudos/article/view/663> Acesso em: 10 mar. 2017.

MOUFFE, Chantal. Liberalismo, pluralismo y ciudadanía democrática. México: Instituto Federal Electoral. 1997b.

ROSENFIELD, Denis. O que é democracia. São Paulo: Brasiliense, 2003.

TRINDADE, Helgio. Reforma Política: Os Desafios da democracia social. In: BENEVIDES, Maria Victoria; VANNUCHI, Paulo; KERCHE, Fábio (Orgs.). Reforma Política e Cidadania. São Paulo: Ed. Fundação Perseu Abramo, 2003. p. 57-82.

VIEIRA, Reginaldo de Souza. A cidadania na República Participativa: pressupostos para a articulação de um novo paradigma jurídico e político para os Conselhos de Saúde. 2013. 540p. Tese (Doutorado em Direito). Programa de Pós-Graduação em Direito, Universidade Federal de Santa Catarina, Centro de Ciências Jurídicas. Florianópolis, 2013. 